\title{
Karakteristik Fisikokimia Tapioka Teroksidasi dengan Oksidator Hidrogen Peroksida dan Katalisis Irradiasi UV-C
}

\section{Physicochemical Properties of Oxidized Cassava Starch using Hydrogen peroxide Catalyzed by $U V$-C Irradiation}

\author{
Angela Myrra Puspita Dewi ${ }^{1 *}$, Haryadi $^{2}$, Sardjono $^{2}$, Eduard F. Tethool ${ }^{1}$ \\ ${ }^{1}$ Jurusan Teknologi Pertanian, Fakultas Teknologi Pertanian, Universitas Papua \\ ${ }^{2}$ Jurusan Teknologi Pangan dan Hasil Pertanian, Fakultas Teknologi Pertanian, Universitas Gadjah Mada \\ *Email: a.puspita@unipa.ac.id
}

\begin{abstract}
Modification of starch could be done through oxidation reactions using hydrogen peroxide $\left(\mathrm{H}_{2} \mathrm{O}_{2}\right)$ catalyzed by UV-C irradiation. The purpose of this study was to determine the effect of $\mathrm{H}_{2} \mathrm{O}_{2}$ concentration and UV-C irradiation time on the physicochemical properties of oxidized tapioca. This study used a factorial completely randomized design, $\mathrm{H}_{2} \mathrm{O}_{2}$ concentration $(1 \%$, 2\%, and $3 \%)$ and irradiation time (5, 10 and 15 minutes). The factors that influence the oxidation reaction studied in this study include levels of carbonyl, carboxyl, amylose, paste properties, development power and solubility of starch. The treatment of hydrogen peroxide concentration and UV irradiation time affected the physicochemical characteristics of oxidized tapioca. Higher concentration of hydrogen peroxide decrease the level of carbonyl, amylose and viscosity of the oxidized starch paste. Whereas the longer the time of UV C irradiation, carbonyl content and the viscosity of the oxidized starch paste were lower, but the carboxyl content produced increases then decreases with the longer the irradiation. The highest carbonyl content was obtained from $3 \% \mathrm{H}_{2} \mathrm{O}_{2}$ treatment, 5 minutes irradiation time was $0.56 \%$ with peak viscosity $2800 \mathrm{cp}$, final viscosity $1500 \mathrm{cp}$, amylose content $23.67 \%(\mathrm{db})$, swelling power $37,23 \%$, solubility $28.89 \%$. Otherwise, the highest carboxyl content was obtained from $1 \% \mathrm{H}_{2} \mathrm{O}_{2}$ treatment, 10 minutes irradiation time was $0.33 \%$ with peak viscosity $4250 \mathrm{cp}$, final viscosity $3005 \mathrm{cp}$, amylose content $24.37 \%(\mathrm{db})$, swelling power $31.92 \%$, and solubility $21.55 \%$.
\end{abstract}

Keywords: tapioca, oxidized starch, hydrogen peroxide, $U V-C$.

\begin{abstract}
Abstrak
Modifikasi pati dapat dilakukan melaluireaksi oksidasi menggunakan hidrogen peroksida $\left(\mathrm{H}_{2} \mathrm{O}_{2}\right)$ dan dikatalisis irradiasi UV-C. Tujuan dari penelitian ini adalah untuk mengetahui pengaruh konsentrasi $\mathrm{H}_{2} \mathrm{O}_{2}$ dan waktu irradiasi UV-C terhadap sifat fisikokimia tapioka teroksidasi. Penelitian ini mengunakan rancangan acak lengkap faktorial yaitu konsentrasi $\mathrm{H}_{2} \mathrm{O}_{2}(1 \%, 2 \%$, dan $3 \%)$ dan waktu irradiasi $(5,10$, dan 15 menit). Faktor-faktor yang berpengaruh terhadap reaksi oksidasi dikaji dalam penelitian ini meliputi kadar karbonil, karboksil, amilosa, sifat pasta, daya pengembangan dan kelarutan pati. Perlakuan konsentrasi hidrogen peroksida dan waktu irradiasi UV berpengaruh terhadap karakteristik fisikokimia tapioka teroksidasi. Makin tinggi konsentrasi hidrogen peroksida, maka kadar karbonil, amilosa, dan viskositas pasta pati oksidasi yang dihasilkan lebih rendah. Sedangkan makin lama waktu irradiasi UV C, kadar karbonil, dan viskositas pasta pati oksidasi yang dihasilkan lebih rendah, namun kadar karboksil yang dihasilkan meningkat kemudian menurun dengan makin lamanya irradiasi. Kadar karbonil tertinggi diperoleh dari perlakuan $\mathrm{H}_{2} \mathrm{O}_{2} 3 \%$, waktu irradiasi 5 menit sebesar $0,56 \%$ dengan viskositas puncak $2800 \mathrm{cp}$, viskositas akhir $1500 \mathrm{cp}$, kadar amilosa $23,67 \%$ (bk), swelling power $37,23 \%$, kelarutan $28,89 \%$. Sedangkan kadar karboksil tertinggi diperoleh dari perlakuan $\mathrm{H}_{2} \mathrm{O}_{2} 1 \%$, waktu irradiasi 10 menit sebesar $0,33 \%$ dengan viskositas puncak $4250 \mathrm{cp}$, viskositas akhir $3005 \mathrm{cp}$, kadar amilosa 24,73\% (bk), swelling power 31,92\%, dan kelarutan $21,55 \%$.
\end{abstract}

Kata kunci: tapioka, pati oksidasi, hidrogen peroksida, UV-C. 


\section{PENDAHULUAN}

Ubi kayu (Manihot esculenta Cranz) merupakan produk hasil pertanian yang berbatang kokoh dan tumbuh di sebagian besar Asia, Afrika, dan Amerika Selatan. Potensi ubi kayu di Indonesia cukup tinggi, dengan produksi yang terus mengalami peningkatan dari 19,053 ton pada tahun 2017 menjadi 19,341 ton di tahun 2018 (Kementerian Pertanian, 2018) Salah satu bagian dari ubi kayu yang paling banyak dimanfaatkan adalah pati. Kandungan pati ubi kayu berkisar antara $73,7-84,9 \%$ per berat kering ubi kayu (Bertollini, 2010). Pati dari ubi kayu atau tapioka memiliki sifat kapasitas penyerapan air yang tinggi, dan suhu gelatinisasi yang rendah (Hill dkk., 1999). Namun, sama halnya dengan pati yang lain, pemanfaatan tapioka dalam industri pangan dan non pangan masih terbatas ditinjau dari sifat fisikokimiawinya seperti retrogradasi cepat, warna gel yang keruh, stabilitas relative rendah. Dengan demikian, diperlukan modifikasi pati untuk mengubah karakteristik fisikokimia pati alaminya (Bertollini, 2010).

Oksidasi pati merupakan salah satu bentuk modifikasi yang banyak digunakan karena menghasilkan pati yang memiliki viskositas rendah, stabilitas pasta tinggi, kejernihan pasta tinggi, sebagai pembentuk film yang baik, dan memiliki sifat perekat yang baik (Perez dkk, 2005). Selama proses oksidasi, gugus hidroksil pada molekul pati akan teroksidasi menjadi gugus karboksil dan karbonil. Reaksi oksidasi juga mengakibatkan terjadinya degradasi molekul pati sehingga viskositas pasta rendah. Beberapa reagen oksidator yang digunakan untuk reaksi oksidasi seperti hidrogen peroksida, sodium hipoklorit, dan permanganat. Hidrogen peroksida banyak digunakan sebagai oksidator pada reaksi oksidasi karena ekonomis dan ramah lingkungan. Hasil sampingan dari reaksi oksidasi dengan hidrogen peroksida sebagai oksidator berupa $\mathrm{H}_{2} \mathrm{O}$ dan $\mathrm{O}_{2}$ sehingga aman digunakan (El-sheikh dkk., 2010). Batas maksimum penggunaan hydrogen peroxide pada pati sebesar 0,15\% (FDA, 2018). Gugus karbonil merupakan gugus fungsional utama yang dihasilkan dari reaksi oksidasi pati menggunakan hidrogen peroksida (Sangseethong dkk., 2010).
Irradiasi UV untuk modifikasi pati telah dilakukan oleh Bertollini dkk., (2000) dan Fiedorowicz dkk., (1999). Modifikasi pati melalui irradiasi UV mengakibatkan degradasi oksidatif yang dipengaruhi oleh intensitas sinar dan lama waktu penyinaran. Makin pendek panjang gelombang sinar UV, maka energi yang digunakan untuk mengkatalisa suatu reaksi makin meningkat (Fiedorowicz dkk., 1999). Sriroth dkk. (2005) melaporkan modifikasi melalui asidifikasi disertai dengan pemaparan energy UV menghasilkan depolimerisasi parsial pada molekul pati singkong. El-sheikh dkk. (2010) telah mengembangkan metode oksidasi pati beras dengan menggunakan penyinaran UV-C (panjang gelombang $190 \mathrm{~nm}$ ) dan adanya hidrogen peroksida sebagai fotosensitizer. Faktor-faktor yang berpengaruh terhadap karakteristik pati oksidasi adalah rasio pati:air, konsentrasi hidrogen peroksida, dan lama waktu irradiasi UV. Kondisi optimal untuk menghasilkan pati beras teroksidasi adalah konsentrasi hidrogen peroksida $0,4 \%$, rasio pati/larutan 1:6, dan lama penyinaran 4 jam. Pati beras teroksidasi yang dihasilkan memiliki sifat fisikokimia meliputi kadar karbonil sebesar 12.2 meq/100 g pati, kadar karboksil sebesar $18.2 \mathrm{meq} / 100 \mathrm{~g}$ pati dan viskositas sebesar 5000 c.pas.

Modifikasi pati singkong melalui oksidasi dengan oksidator hidrogen peroksida yang dikatalisis irradiasi UV belum dilakukan. Dengan demikian, dalam penelitian ini akan dikaji bagaimana pengaruh oksidasi tapioka dengan oksidator hidrogen peroksida dengan katalisis irradiasi UV-C terhadap sifat fisikokimia pati teroksidasi yang dihasilkan.

\section{METODOLOGI}

\section{Bahan dan alat}

Bahan yang digunakan untuk pembuatan pati oksidasi adalah ubi kayu varietas ADIRA 4 dari Cangkringan, Sleman, Yogyakarta. Sedangkan bahan kimia yang digunakan dalam penelitian ini adalah hidrogen peroksida berkualifikasi teknis dengan tingkat kemurnian 50\%, dan bahan kimia pro analisis untuk keperluan analisa meliputi $\mathrm{HCl}$ (Sigma), hydroxylamine hydrochloride (Merck), kristal $\mathrm{NaOH}$ (Sigma), indikator phenolphtalein. 
Peralatan yang digunakan dalam penelitian ini meliputi fotoreaktor yang terdiri dari : pompa, lampu UV dengan panjang gelombang $100-$ $280 \mathrm{~nm}$, tempat bahan (Gambar 1), cabinet dryer, desikator, timbangan analitik, vortex, spektrofotometer UV-Vis, Brabender viscoamylograph, oven, Chromameter Minolta, waterbath shaker, dan peralatan gelas untuk analisis kimia.

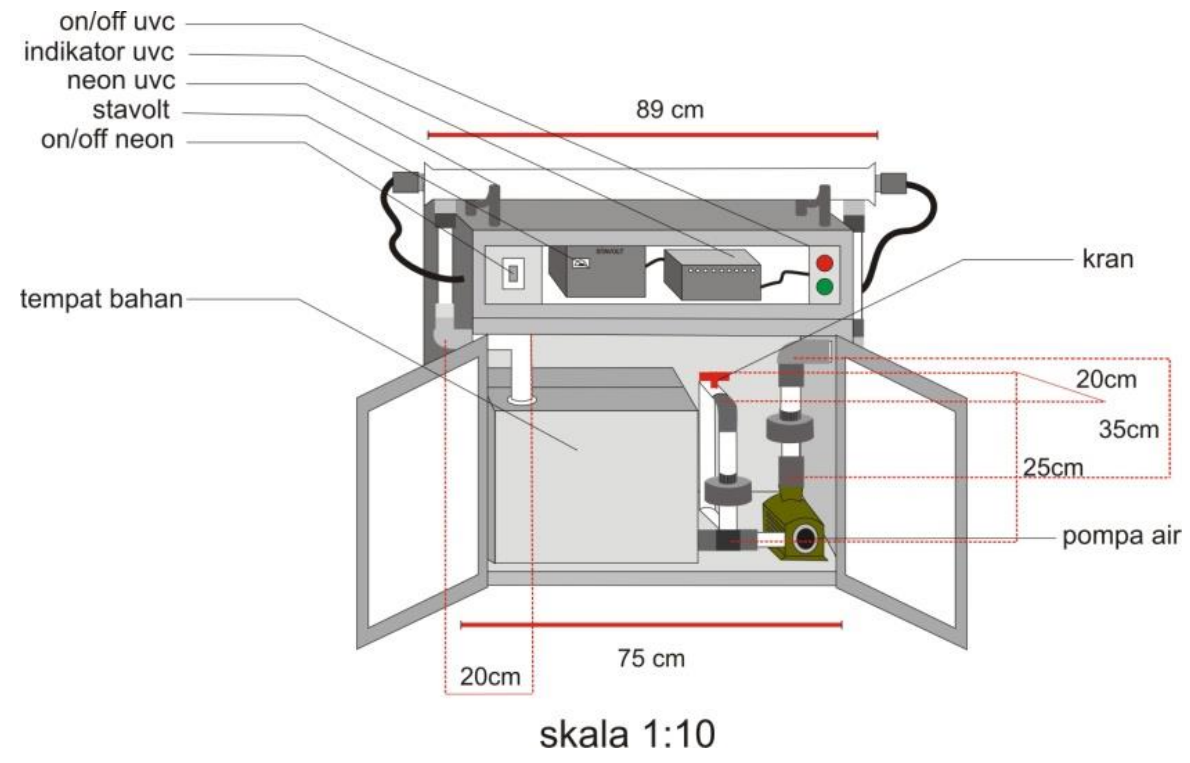

Gambar 1. Skema Alat Fotoreaktor

\section{Metode Penelitian}

\section{Pembuatan Pati Oksidasi}

Pembuatan pati oksidasi mengikuti metode (El-sheikh dkk., 2010) dengan sedikit modifikasi. Tapioka hasil ekstraksi dalam bentuk pati basah dilakukan penyiapan slurry untuk mendapatkan rasio pati basah : aquades sebesar 1:6. Slurry pati dengan rasio pati : aquades yang telah disiapkan dimasukkan dalam stainlees steel box kemudian slurry pati dioksidasi dengan penambahan hidrogen peroksida dengan variasi konsentrasi 1, 2 dan 3\% (basis berat pati kering). Slurry pati dialirkan melalui lampu UV dengan variasi waktu 5 menit, 10 menit, dan 15 menit. Kemudian slurry pati disentrifugasi dan dilakukan pencucian dengan aquades sebanyak 3 kali untuk menghilangkan residu hidrogen peroksida. Pati oksidasi selanjutnya dilakukan pengeringan pada suhu $40^{\circ} \mathrm{C}$ dengan cabinet dryer selama 12 jam. Selanjutnya pati oksidasi dianalisis sifat fisikokimia yang meliputi kadar karbonil dan karboksil (Zhang dkk., 2009), amilosa (AOAC, 1984), viskositas pasta (Brabender viscoamylograph), daya pengembangan dan kelarutan pati (Adebowale dkk., 2009).

\section{Penentuan kadar karbonil dan karboksil}

(Zhang dkk., 2009). Penentuan kadar karbonil dan karboksil mengikuti metode Zhang dkk. (2009). Kadar karbonil ditentukan dengan melarutkan $2 \mathrm{~g}$ sampel dalam $100 \mathrm{ml}$ aquades kemudian larutan digelatinisasi pada suhu $100^{\circ} \mathrm{C}$ selama 20 menit. Selanjutnya dilakukan pendinginan hingga mencapai suhu $40^{\circ} \mathrm{C}$ dan dilakukan pengaturan $\mathrm{pH}$ hingga mencapai 3,2 dengan penambahan $0,1 \mathrm{~N} \mathrm{HCl}$ kemudian dilakukan penambahan $15 \mathrm{ml}$ reagen hydroxylamine $(25 \mathrm{gr}$ hydroxylamine dilarutkan dalam $100 \mathrm{ml} \mathrm{NaOH} \quad 0,5 \quad \mathrm{~N}$ ). Selanjutnya dilakukan pemanasan dalam waterbath pada suhu $40^{\circ} \mathrm{C}$ selama 4 jam disertai dengan pengadukan lambat. Sisa hydroxylamine ditentukan dengan titrasi menggunakan $0,1 \mathrm{~N} \mathrm{HCl}$, dan larutan blanko hanya berisi reagen hydroxylamine dengan perlakuan yang sama. Kadar karbonil dihitung dengan persamaan sebagai berikut :

\footnotetext{
$\%$ Karbonil $=$

(ml blangko-ml sampel)x N asam x 0,028 x 100 berat sampel (dry basis)
} 
Kadar karboksil ditentukan dengan melarutkan 5 g sampel dengan $25 \mathrm{ml} \mathrm{0,1} \mathrm{N} \mathrm{HCl} \mathrm{kemudian}$ dilakukan pengadukan selama 30 menit dengan magnetic stirer. Selanjutnya dilakukan penyaringan slurry kemudian dibilas dengan $300 \mathrm{ml}$ aquades. Pati hasil penyaringan selajutnya ditambah aquades hingga volume mencapai $300 \mathrm{ml}$ kemudian dipanaskan pada suhu $100^{\circ} \mathrm{C}$ selama 15 menit disertai dengan pengadukan. Larutan yang telah dingin selanjutnya dititrasi dengan $0,1 \quad \mathrm{~N} \quad \mathrm{NaOH}$ hingga $\mathrm{pH}$ mencapai 8,3, blangko berupa tapioka alami. Perhitungan kadar karboksil ditentukan dengan persamaan sebagai berikut :

$\%$ karboksil =

(ml sampel-ml blangko)x N NaOH x 0,045 x 100 berat sampel (dry basis)

\section{Penentuan kadar amilosa}

Kadar amilosa ditentukan dengan mengikuti metode AOAC (1984). Sebanyak $100 \mathrm{mg}$ sampel pati dimasukkan ke dalam tabung reaksi, ditambahkan $1 \mathrm{ml}$ etanol 95\% dan $9 \mathrm{ml} \mathrm{NaOH} 1 \mathrm{~N}$. Campuran dipanaskan dalam air mendidih selama 10 menit dan ditambahkan dengan aquades sampai tanda tera. Larutan tersebut diambil $5 \mathrm{ml}$, dimasukkan dalam labu takar $100 \mathrm{ml}$, ditambahkan $1 \mathrm{ml}$ asam asetat $1 \mathrm{~N}$ dan $2 \mathrm{ml}$ iod $0,2 \%$. Larutan dalam labu takar ditambahkan aquades sampai tanda tera, lalu dibiarkan 20 menit dan intensitas warna biru ditera dengan spektrofotometer pada $\lambda 625 \mathrm{~nm}$. Kadar amilosa sampel dihitung dengan persamaan :

$\%$ amilosa $=\frac{X \times 2000 \times 100}{\text { berat sampel }(\mathrm{mg})} \times 100 \%$

Di mana $\mathrm{X}=$ konsentrasi amilosa dari kurva standar amilosa

\section{Pengujian viskositas pasta}

Viskositas pasta diukur mengunakan alat Brabender viscoamylograph. $1 \mathrm{~g}$ tepung (100 mesh) dimasukkan ke dalam sample chamber viscometer kemudian dilarutkan dengan aquades $10 \mathrm{ml}$ dan dilakukan pengadukan. Spindle pada alat pengaduk dipasang dan dihubungkan dengan sample chamber ke alat sirkulasi pemanas lalu hubungkan kabel pemantau panas dari alat utama viskometer ke sample chamber. Suhu pemanasan dari alat diatur sampai $30^{\circ} \mathrm{C}$ kemudian alat DV II-Pro viskometer dihidupkan dan isikan semua parameter operasional (kecepatan putaran spindle, interval waktu pemanasan, nomor spindle yang digunakan, waktu total analisa). Setelah itu suhu alat sirkulasi panas diatur hingga suhu $95^{\circ} \mathrm{C}$. Selanjutnya akan diperoleh data berupa grafik perubahan viskositas pasta selama pemanasan.

\section{Pengujian Swelling Power (daya pengembangan) dan kelarutan pati}

Penentuan swelling power dan kelarutan pati mengikuti metode Adebowale dkk. (2009). Sampel pati 1 g dimasukkan ke dalam tabung pengujian kemudian tabung yang telah berisi sampel ditimbang (W1). Selanjutnya pati dilarutkan dengan aquades hingga volume $50 \mathrm{ml}$ kemudian kocok hingga homogen menggunakan vortex. Larutan pati dipanaskan pada suhu $95^{\circ} \mathrm{C}$ selama 30 menit kemudian didinginkan hingga suhu $30 \pm 2^{\circ} \mathrm{C}$ dan sentrifugasi (500 rpm, 15 menit). Larutan gel dan aliquot dilakukan pemisahan kemudian larutan gel dan tabung ditimbang sebagai W2. Sedangkan $5 \mathrm{ml}$ aliquot (fase jernih) diambil dan dimasukkan dalam botol timbang yang telah diketahui berat konstannya. Selanjutnya aliquot dikeringkan pada suhu $110^{\circ} \mathrm{C}$ dan ditimbang hingga berat konstan. Residu ditentukan setelah pengeringan dan dihitung sebagai jumlah pati yang terlarut dalam air sedangkan swelling power dihitung dengan persamaan berikut :

Swelling power $(\%)=\frac{\mathrm{W} 2-\mathrm{W} 1(\mathrm{~g})}{\text { berat pati }(\mathrm{g})} \times 100 \%$

\section{HASIL DAN PEMBAHASAN}

\section{Kadar karbonil dan karboksil}

Salah satu indikator keberhasilan reaksi oksidasi pati adalah terbentuknya gugus karbonil dan karboksil (Zavareze dkk., 2012) Hasil pengujian kadar karbonil dan karboksil pati oksidasi dapat dilihat pada Tabel 1. Kadar karbonil tapioka teroksidasi dipengaruhi oleh konsentrasi $\mathrm{H}_{2} \mathrm{O}_{2}$ dan waktu irradiasi UV. Kadar karbonil meningkat dengan makin tingginya konsentrasi $\mathrm{H}_{2} \mathrm{O}_{2}$, tetapi menurun seiring makin lamanya waktu irradiasi UV-C. Sedangkan kadar karboksil hanya dipengaruhi oleh lama waktu irradiasi UV-C, di mana kadar karboksil meningkat pada menit ke-10 dan menurun pada menit ke-15. Pada 
perlakuan lama waktu irradiasi UV-C 10 menit, kadar karboksil yang dihasilkan lebih tinggi daripada kadar karboksil pada perlakuan lama waktu UV 5 dan 15 menit. Kadar karboksil yang lebih rendah pada perlakuan lama waktu irradiasi 15 menit kemungkinan terjadi karena reaksi dekarboksilasi (El-sheikh dkk., 2010), sedangkan kadar karbonil yang lebih rendah kemungkinan disebabkan karena reaksi oksidasi karbonil menjadi karboksil (Sangseethong dkk., 2010).

Selama proses oksidasi, gugus hidroksil pada molekul pati teroksidasi menjadi gugus karbonil kemudian menjadi gugus karboksil
(Zavareze dkk., 2012). Proses tersebut dipengaruhi oleh jenis oksidator yang digunakan dan kondisi reaksinya. Reaksi paralel di mana gugus karbonil dan karboksil secara selektif yang terbentuk akibat oksidasi oleh gugus hidroksil pada posisi tertentu yaitu C-2, C-3 dan C-6 dari cincin glukosidik (Kuakpetoon dan Wang, 2006). Pembentukan gugus karbonil pada pati oksidasi tersebut dapat menurunkan permeabilitas uap air pada produk termoplastik berbasis pati (Zhang dkk., 2009).

Tabel 1. Kadar Karbonil dan Karboksil Tapioka Teroksidasi

\begin{tabular}{cccc}
\hline Konst. $\mathrm{H}_{2} \mathrm{O}_{2}$ & $\begin{array}{c}\text { Waktu irradiasi UV } \\
\text { (menit) }\end{array}$ & Karbonil (\%db) & Karboksil (\%db) \\
\hline \multirow{2}{*}{$1 \%$} & 5 & $0,18^{\mathrm{aA}}$ & $0,19^{\mathrm{A}}$ \\
& 10 & $0,28^{\mathrm{aB}}$ & $0,33^{\mathrm{B}}$ \\
& 15 & $0,14^{\mathrm{aB}}$ & $0,22^{\mathrm{C}}$ \\
\hline \multirow{2}{*}{$2 \%$} & 5 & $0,13^{\mathrm{aA}}$ & $0,18^{\mathrm{A}}$ \\
& 10 & $0,12^{\mathrm{aB}}$ & $0,29^{\mathrm{B}}$ \\
& 15 & $0,09^{\mathrm{aB}}$ & $0,24^{\mathrm{C}}$ \\
\hline & 5 & $0,56^{\mathrm{bA}}$ & $0,11^{\mathrm{A}}$ \\
& 10 & $0,25^{\mathrm{bB}}$ & $0,29^{\mathrm{B}}$ \\
& 15 & $0,22^{\mathrm{bB}}$ & $0,29^{\mathrm{C}}$ \\
\hline
\end{tabular}

Keterangan :

- Superskrip dengan huruf yang sama menunjukkan tidak ada perbedaan yang nyata $(\mathrm{P}<0,05)$

- a,b,c menunjukkan perbedaan nyata untuk faktor konsentrasi hidrogen peroksida

- A,B,C menunjukkan perbedaan nyata untuk faktor waktu irradiasi UV

\section{Kadar amilosa}

Kadar amilosa tapioka teroksidasi disajikan dalam Tabel 2. Dibandingkan dengan tapioka alami, kadar amilosa pati oksidasi lebih tinggi daripada kadar amilosa tapioka alami di mana kadar amilosa tapioka alami $22,09 \%$. Peningkatan kadar amilosa mengakibatkan penurunan viskositas puncak dan viskositas akhir namun meningkatkan suhu gelatinisasi, dan menghambat permeabilitas terhadap gas pada produk biodegradable film (Li dkk., 2008). Selain itu, pati dengan kandungan amilosa tinggi juga memiliki kandungan pati resisten (RS) yang lebih tinggi daripada pati dengan kandungan amilosa rendah (Vanier dkk., 2016). Dari Tabel 2, kadar amilosa tapioka teroksidasi dipengaruhi oleh waktu irradiasi UV-C. Makin lama irradiasi UV-C, kadar amilosa yang dihasilkan lebih tinggi.

Kadar amilosa mengalami peningkatan kemungkinan disebabkan karena terjadinya depolimerisasi molekul amilopektin (Kuakpetoon -dan Wang, 2006). Amilopektin bersifat amorf sehingga pada daerah ini mudah mengalami oksidasi oleh oksidator pada atom C-2 atau C-3 membentuk gugus karbonil dan karboksil selain itu juga dapat mengalami depolimerisasi pada ikatan 1,4 atau 1,6 glikosidik. Wang dan Wang (2005) menyatakan bahwa molekul amilopektin lebih mudah didepolimerisasi dengan $\mathrm{H}_{2} \mathrm{O}_{2}$. Terjadinya depolimerisasi pada molekul amilopektin akan menghasilkan potongan rantai pendek yang linear sehingga ketika direaksikan dengan larutan iod, kadar amilosa 
akan tampak meningkat. Kadar karbonilkarboksil dan derajat depolimerisasi pada pati oksidasi merupakan indikator penentu derajat oksidasi (Kuakpetoon danWang, 2006).

Tabel 2. Kadar Amilosa Tapioka Teroksidasi Waktu

Konst. $\mathrm{H}_{2} \mathrm{O}_{2}$ irradiasi UV Amilosa (\%db) (menit)

\begin{tabular}{ccc}
\hline $1 \%$ & 5 & $23,98^{\mathrm{A}}$ \\
& 10 & $24,73^{\mathrm{A}}$ \\
$2 \%$ & 15 & $23,70^{\mathrm{A}}$ \\
& 5 & $25,08^{\mathrm{B}}$ \\
& 10 & $25,60^{\mathrm{B}}$ \\
$3 \%$ & 15 & $23,76^{\mathrm{B}}$ \\
& 5 & $23,67^{\mathrm{B}}$ \\
& 10 & $25,26^{\mathrm{B}}$ \\
& 15 & $25,13^{\mathrm{B}}$ \\
\hline
\end{tabular}

Keterangan :

- Superskrip dengan huruf yang sama menunjukkan tidak ada perbedaan yang nyata $(\mathrm{P}<0,05)$

- A,B,C menunjukkan perbedaan nyata untuk faktor waktu irradiasi UV

\section{Viskositas Pasta}

Konsentrasi hidrogen peroksida dan waktu irradiasi UV berpengaruh terhadap viskositas pasta tapioka teroksidasi. Pengaruh konsentrasi hydrogen peroksida terhadap viskositas pati teroksidasi dapat dilihat pada Gambar 2, sedangkan pengaruh waktu irradiasi UV dapat dilihat dari Gambar 3. Konsentrasi hidrogen peroksida sebesar $1 \%$ dan $2 \%$ tidak berbeda nyata, namun jika dibandingkan dengan viskositas puncak dan viskositas akhir tapioka alami, viskositas tapioka teroksidasi yang dihasilkan dari perlakuan konsentrasi hydrogen peroksida $1 \%$ dan $2 \%$ lebih tinggi.

Tapioka teroksidasi dari perlakuan konsentrasi hydrogen peroksida 3\% menunjukkan viskositas puncak yang lebih tinggi dari viskositas puncak tapioka alami, namun viskositas akhirnya lebih rendah daripada viskositas puncak tapioka alami. Viskositas puncak dan akhir tapioka teroksidasi menurun dengan makin tingginya konsentrasi $\mathrm{H}_{2} \mathrm{O}_{2}$. Viskositas puncak pati oksidasi menggambarkan degradasi granula pati, di mana hal tersebut dipengaruhi oleh sumber pati dan kondisi reaksi oksidasi (Vanier dkk., 2016). Tingginya viskositas puncak tersebut kemungkinan disebabkan karena level oksidasi yang rendah sehingga terjadi rearrangement permukaan molekul granula tanpa merusak ikatan glikosidik (Renato dkk., 2011). Dengan demikian akan terjadi pembentukan senyawa intermediet yang meningkatkan ketahanan granula pati selama pemanasan dan meningkatkan penggelembungan granula (Perez dkk., 2005).

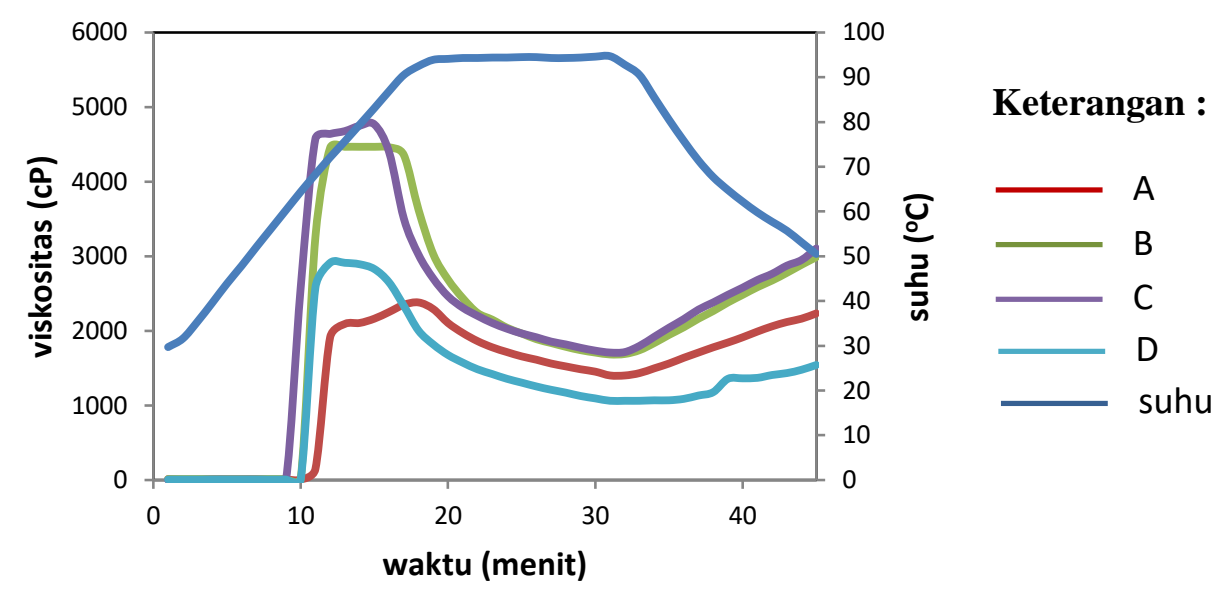

Gambar 2. Pengaruh konsentrasi $\mathrm{H}_{2} \mathrm{O}_{2}$ terhadap viskositas pasta tapioka teroksidasi (A : tapioka alami ; $\mathrm{B}: \mathrm{H}_{2} \mathrm{O}_{2} 1 \%$ (b/bk); C : $\mathrm{H}_{2} \mathrm{O}_{2} 2 \%$ (b/bk); D : $\mathrm{H}_{2} \mathrm{O}_{2} 3 \%$ (b/bk) )

Waktu irradiasi juga berpengaruh terhadap viskositas pasta tapioka teroksidasi.
Lama irradiasi UV 5 menit menghasilkan viskositas puncak dan akhir tapioka teroksidasi 
yang paling tinggi dari tapioka alami dan perlakuan waktu irradiasi 10 dan 15 menit. Perlakuan B (lama waktu irradiasi 10 menit) menghasilkan viskositas puncak tapioka teroksidasi yang lebih tinggi dari tapioka alami dan tapioka teroksidasi dengan lama waktu irradaisi 15 menit, tetapi viskositas akhirnya lebih rendah daripada tapioka alami. Secara umum viskositas puncak dan akhir tapioka teroksidasi menurun dengan makin lamanya waktu irradiasi UV. Penurunan viskositas puncak dan akhir dengan makin lamanya irradiasi UV kemungkinan disebabkan karena terjadinya depolimerisasi amilosa atau amilopektin pada bagian amorf (Bertollini dkk., 2000). Oksidasi dapat menghambat retrogradasi pati, hal ini tampak tidak terjadinya peningkatan viskositas pasta setelah pendinginan yang cukup signifikan.dari perlakuan konsentrasi $\mathrm{H}_{2} \mathrm{O}_{2}$ dengan waktu irradiasi 10 dan 15 menit (Gambar 3). Hal ini deisebabkan karena pembentukan gugus karboksil selama reaksi oksidasi sehingga repulse antar gugus karboksil mengakibatkan penghambatan retrogradasi, selain itu keberadaan gugus karbonil dan karboksil juga meningkatkan jarak antar rantai amilosa (Vanier dkk., 2016). Penghambatan retrogradasi pati tersebut menggambarkan stabilitas pati oksidasi yang lebih tinggi dari pati alami sehingga dapat direkomendasikan untuk diaplikasikan pada produk frozen food, pudding, whipped cream, atau produk bakery.
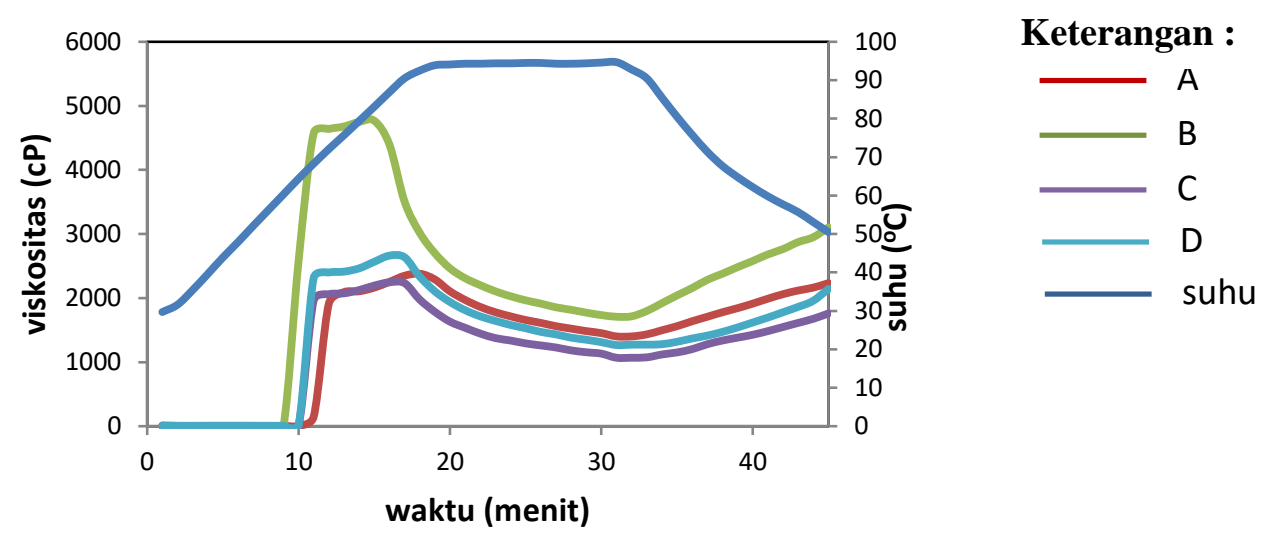

Gambar 3. Pengaruh waktu irradiasi UV-C terhadap viskositas pasta tapioka teroksidasi (A : tapioka alami ; B:waktu irradiasi 5 menit ; C:waktu irradiasi 10 menit; D:waktu irradiasi 15 menit)

Viskositas pasta pati yang rendah menunjukkan bahwa selama proses oksidasi terjadi reaksi hidrolisis ikatan glikosidik yang mengarah pada depolimerisasi sehingga terjadi penurunan berat molekul (Wang dan Wang, 2005). Namun pada beberapa sampel perlakuan, viskositas pasta pati oksidasi lebih tinggi daripada viskositas puncak pasta tapioka alami dengan pola yang menyerupai kurva amilografi tapioka alami. Hal ini kemungkinan disebabkan karena terjadi slight oxidation (oksidasi ringan) sehingga membentuk hemiketal atau hemiasetal crosslink yang diasumsikan terjadi di antara molekul amilopektin dan kemungkinan kecil berada di antara molekul amilosa dan amilopektin (Kuakpetoon dan Wang, 2006). Dewi dkk. (2014) melaporkan kombinasi perlakuan oksidasi dan irradiasi UV pada pati sagu teroksidasi meningkatkan viskositas pasta karena terjadi fotocrosslinking. Crosslinking yang terbentuk akibat reaksi oksidasi berbeda dengan crosslinking pati secara kimia. Fenomena tersebut dapat dilihat berdasarkan suhu pasting pati oksidasi lebih rendah daripada suhu pasting tapioka alami, di mana suhu pasting tapioka alami $89,5^{\circ} \mathrm{C}$ sedangkan suhu pasting pati oksidasi berkisar antara 59,7 - $85,8^{\circ} \mathrm{C}$. Tapioka teroksidasi dengan tipe viskositas pasta tersebut direkomendasikan untuk diaplikasikan sebagai biodegradable plastic (Vanier dkk., 2016).

\section{Swelling power dan Kelarutan}

Swelling power menunjukkan seberapa besar granula pati dapat mengembang yang ditunjukkan dengan pertambahan berat karena adanya penyerapan air oleh granula pati. Ketika larutan pati dipanaskan, terjadi kerusakan pada struktur kristalin pati karena 
putusnya ikatan hidrogen, dan molekul air akan terikat oleh ikatan hidrogen pada gugus hidroksil dari amilosa dan amilopektin. Hal ini mengakibatkan peningkatan pengembangan dan kelarutan granula pati. Saat kondisi tersebut dilanjutkan, granula pati akan pecah dan amilosa akan terdispersi keluar dan larut dalam larutan.

Swelling power dan kelarutan pati oksidasi dapat dilihat pada Tabel 3. Swelling power dan kelarutan pati teroksidasi dipengaruhi oleh konsentrasi hidrogen peroksida, sedangkan lama irradiasi UV tidak berpengaruh nyata terhadap swelling power dan kelarutan tapioka teroksidasi. Makin tinggi konsentrasi hidrogen peroksida, swelling power pati oksidasi yang meningkat demikian juga dengan kelarutan pati. Peningkatan swelling power kemungkinan berkaitan dengan pembentukan gugus hidrofilik $(\mathrm{COOH})$ selama reaksi oksidasi (Lee dkk., 2005). Namun jika dibandingkan dengan swelling power tapioka alami, swelling power tapioka teroksidasi lebih rendah. Fenomena ini kemungkinan disebabkan karena oksidasi menyebabkan perubahan struktur granula menjadi lebih porus sehingga kemampuan dalam menghidrasi air pada saat pemanasan tinggi namun saat sentrifugasi air yang terabsorb akan keluar karena ketahanan granula dalam memerangkap air lemah (Wang dan Wang, 2005).

Kelarutan diindikasikan sebagai jumlah molekul pati yang terlarut pada berbagai suhu. Hasil penelitian menunjukkan bahwa kelarutan pati dipengaruhi oleh konsentrasi hidrogen peroksida. Jika dibandingkan dengan kelarutan tapioka alami, kelarutan pati oksidasi lebih tinggi. Hal ini kemungkinan disebabkan karena terjadinya depolimerisasi dan lemahnya struktur granula pati akibat oksidasi (Adebowale dkk., 2002).

Tabel 3. Swelling power dan kelarutan Tapioka Alami dan Tapioka Teroksidasi

\begin{tabular}{cccc}
\hline Konsentrasi $\mathrm{H}_{2} \mathrm{O}_{2}$ & $\begin{array}{c}\text { Waktu irradiasi UV } \\
\text { (menit) }\end{array}$ & Swelling power (\%) & Kelarutan (\%) \\
\hline Native & 5 & 39.1 & 21,57 \\
& 10 & $31,92^{\mathrm{a}}$ & $21,55^{\mathrm{a}}$ \\
$1 \%$ & $31,55^{\mathrm{a}}$ & $21,36^{\mathrm{a}}$ \\
& 15 & $32,87^{\mathrm{a}}$ & $22,58^{\mathrm{a}}$ \\
$2 \%$ & 5 & $31,07^{\mathrm{b}}$ & $19,76^{\mathrm{b}}$ \\
& 10 & $33,45^{\mathrm{b}}$ & $21,10^{\mathrm{b}}$ \\
& 15 & $35,87^{\mathrm{b}}$ & $20,49^{\mathrm{b}}$ \\
$3 \%$ & 5 & $37,23^{\mathrm{b}}$ & $28,89^{\mathrm{b}}$ \\
& 10 & $37,42^{\mathrm{b}}$ & $25,18^{\mathrm{b}}$ \\
& 15 & $40,23^{\mathrm{b}}$ & $25,39^{\mathrm{b}}$ \\
\hline
\end{tabular}

Keterangan :

- Superskrip dengan huruf yang sama menunjukkan tidak ada perbedaan yang nyata $(\mathrm{P}<0,05)$

- a,b,c menunjukkan perbedaan nyata untuk faktor konsentrasi hidrogen peroksida

\section{KESIMPULAN}

Perlakuan konsentrasi hidrogen peroksida dan waktu irradiasi UV berpengaruh terhadap karakteristik fisikokimia tapioka teroksidasi. Makin tingginya konsentrasi hidrogen peroksida, kadar karbonil, dan viskositas pasta pati oksidasi yang dihasilkan lebih rendah sedangkan kadar amilosa meningkat hingga konsentrasi $\mathrm{H}_{2} \mathrm{O}_{2} \quad 2 \%$ kemudian menurun pada perlakuan konsentrasi $\mathrm{H}_{2} \mathrm{O}_{2} 3 \%$. Selain itu swelling power (daya pengembangan) dan kelarutan pati meningkat dengan makin tingginya konsentrasi $\mathrm{H}_{2} \mathrm{O}_{2}$. Makin lama waktu irradiasi UV C, kadar karbonil, dan viskositas pasta pati oksidasi yang dihasilkan lebih rendah, namun kadar karboksil yang dihasilkan dari perlakuan irradiasi UV C 10 menit lebih tinggi dibandingkan dengan kadar karboksil yang 
dihasilkan dari perlakuan irradiasi UV C 5 menit dan 15 menit. Ditinjau dari viskositas pastanya, oksidasi dapat meningkatkan stabilitas pasta pati sehingga dapat direkomendasikan untuk produk bakery dan frozen food, selain itu tingginya swelling power (daya pengembangan), tapioka teroksidasi juga cocok untuk diaplikasikan untuk produk bakery. Sedangkan kelarutan pati yang tinggi dan kaberadaan gugus karbonil pada tapioka teroksidasi cocok untuk diaplikasikan sebagai bahan pembuatan biodegradable plastic. Kadar karbonil tertinggi diperoleh dari perlakuan $\mathrm{H}_{2} \mathrm{O}_{2} 3 \%$, waktu irradiasi 5 menit sebesar $0,56 \%$ dengan viskositas puncak $2800 \mathrm{cp}$, viskositas akhir $1500 \mathrm{cp}$, kadar amilosa 23,67\% (bk), swelling power $37,23 \%$, kelarutan $28,89 \%$. Sedangkan kadar karboksil tertinggi diperoleh dari perlakuan $\mathrm{H}_{2} \mathrm{O}_{2} 1 \%$, waktu irradiasi 10 menit sebesar $0,33 \%$. Dengan viskositas puncak 4250 $\mathrm{cp}$, viskositas akhir $3005 \mathrm{cp}$, kadar amilosa $24,73 \%$ (bk), swelling power $31,92 \%$, kelarutan $21,55 \%$.

\section{DAFTAR PUSTAKA}

Adebowale, K., O., Afolabi, T., A., Lawal, O., S. 2002. Isolation, chemical modification and physicochemical characterization of Bambara groundnut (Voandzeia subterranean) starch and flour. Food Chemistry 78:305-311.

Adebowale, K. O., Henle, T., Schwarzenbolz, U., Doert, T. 2009. Modification and properties of African yam bean (Sphenostylis stenocarpa Hochst. Ex A. Rich.) Harms starch I: Heat moisture treatments and annealing. Food Hydrocolloids 23(7):1947-1957. DOI:10.1016/j.foodhyd.2009.01.002.

Bertollini, A. 2010. Starch Characterization, Properties and Applications. CRC Press, Boca Raton.

Bertollini, A., Mestres, C., Collona. 2000. Rheological Properties of Acidified and UV-Irradiates Starches. Starch/Starke 52:340-344.

Dewi, A. M. P., Tethool, E. F., Jading, A. 2014. Physiscochemical and baking expansion properties of peroxide oxidized sago starch with different UV irradaistions. Asian Journal of Food and Agro-Industry 7(1):6-12.

El-sheikh, M. A., Ramadan, M. A., El-shafie,
A. 2010. Photo-oxidation of rice starch . Part I: Using hydrogen peroxide. Carbohydrate Polymers 80(1):266-269. DOI:10.1016/j.carbpol.2009.11.023.

FDA. 2018. Food for Human Consumption. CFR, USA.

Fiedorowicz, M. T., Tomasik, P., Sangguan, Y., Seung, T. L. 1999. Molecular distribution and pasting properties of UV-irradiated corn starches. Starch/Starke 51:126-131.

Hill, Sandra, E., Sriburi, P., Barclay, F. 1999. Depolymerisation of cassava starch. Carbohydrate Polymers 38:211-218.

Kuakpetoon, D., Wang, Y., J. 2006. Structural Characteristics and Physicochemical Properties of Oxidized Corn Starches Varying in Amylose Content. Carbohydrate Research 341: 1896-1915.

Lee, J., S., Kumar, R., N., Rozman, H., D., Azemi, B., M., N. 2005. Pasting, Swelling, and Solubility Properties of UV initiated Starch-graft-Poly(AA). Food Chemistry 91:203-211.

Li, Y., Shoemaker, C. F., Ma, J., Shen, X., Zhong, F. 2008. Paste viscosity of rice starches of different amylose content and carboxymethylcellulose formed by dry heating and the physical properties of their films. Food Chemistr 109:616-623. DOI:10.1016/j.foodchem.2008.01.023.

Perez, B., Rivera, M. M. S., Suarez, F. J. L. G., del Valle, M. V., Gutierrez-Meraz, F. 2005. Partial characterization of banana starches oxidized by different levels of sodium hypochlorite. Carbohydrate Polymers 62:50-56. DOI:10.1016/j.carbpol.2005.07.005.

Renato, A., Dias, G., Zavareze, R., Cardoso, M., Helbig, E., Oliveira, D., Francisco, C. (2011). Pasting, expansion and textural properties of fermented cassava starch oxidised with sodium hypochlorite. Carbohydrate Polymers 84(1):268-275. DOI: 10.1016/j.carbpol.2010.11.033.

Sangseethong, K., Termvejsayanon, N., Sriroth, K. 2010. Characterization of physicochemical properties of hypochlorite- and peroxide-oxidized cassava starches. Carbohydrate Polymers 82(2):446-453.

DOI:10.1016/j.carbpol.2010.05.003.

Sriroth, K., Watanasuchart, N., Naivikul, O., Charoenrein, S. 2005. Molecular 
proerties of cassava starch modified with different UV irradiations to enhance baking expansion. Carbohydrate Polymers 61:80-87.

Vanier, N. L., Lisie, S., El, M., Renato, A., Dias, G., Zavareze, R. 2016. Molecular structure, functionality and applications of oxidized starches: A review. Food Chemistry 10:138-146. DOI:10.1016/j.foodchem.2016.10.138.

Wang, Y. J., Wang, L. 2005. Physicochemical properties of common and waxy corn starch oxidized by different level of sodium hypochlorite. Carbohydrate Polymers 52:207-217.
Zavareze, E. D. R., Pinto, V. Z., Klein, B., El Halal, S. L. M., Elias, M. C., PrenticeHernández, C., Dias, A. R. G. 2012. Development of oxidised and heatmoisture treated potato starch film. Food Chemistry 132(1)344-350. DOI:10.1016/j.foodchem.2011.10.090.

Zhang, Y. R., Zhang, S. D., Wang, X. L., Chen, R. Y., Wang, Y. Z. 2009. Effect of carbonyl content on the properties of thermoplastic oxidized starch. Carbohydrate Polymers 78(1):157-161. DOI:10.1016/j.carbpol.2009.04.023. 